\title{
Moderating effects of executive function between depression severity and work performance: a web-based cross-sectional study
}

\author{
Tamara Alejandra Sierra-Aparicio,' Brenda Paulina Magaña-Quijano, ' Jacquelyn Vargas-Quiñones, 'Brenda \\ Martínez-García, 'Aldebarán Toledo-Fernández'
}

Escuela de Psicología, Universidad Anáhuac México Sur, Mexico City, Mexico.

Correspondence:

Aldebarán Toledo-Fernández

Universidad Anáhuac México Sur, Escuela de Psicología.

Av. De las Torres 131, Colonia Olivar de los Padres, Delegación Álvaro Obregón, 01780, Ciudad de México.

Email: aldebarantoledo@gmail.com

Received: 7 December 2018

Accepted: 4 April 2019

\section{Citation:}

Sierra-Aparicio, T. A., Magaña-Quijano, B. P., Vargas-Quiñones, J., Martínez-García, B. Toledo-Fernández, A. (2019). Moderating effects of executive function between depression severity and work performance: a web-based cross-sectional study. Salud Mental, 42(2), 59-64.

DOI: $10.17711 /$ SM. $0185-3325.2019 .008$

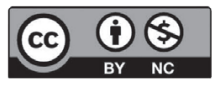

\begin{abstract}
Introduction. Depression and dysexecutive functioning share several neurocognitive features, and both often impair areas of everyday life functioning, such as work. The effect of their interaction on this outcome, however, is barely known. Objective. Was to analyze the moderating effect of executive functioning (EF) on the relation between depression severity and work performance (presenteeism and absenteeism). Method. Data was collected through a non-probabilistic web-based survey. Hierarchical linear regression analyzes were used for testing the main hypothesis, with depression severity (PHQ-9) and EFs (BRIEF-A) as predictors, and presenteeism (SPS-6) and absenteeism (HPQ) as independent outcome variables. Results. There were 462 participants analyzed. The regression models showed no significant interaction, only additive effects of depression severity and EF on presenteeism, and no effect of these variables on absenteeism. Discussion and conclusion. Our main finding disagrees with the moderating effects of EF reported for other psychological variables. We hypothesize that EF alterations may have particular features for depression (e.g., cognitive inflexibility in thought rumination), which are not assessed by the BRIEF-A. Future studies should consider using EF performance tasks to test moderation and using naturalistic indicators of work performance.
\end{abstract}

Keywords: Depression, executive functions, work performance, presenteeism, absenteeism.

\section{RESUMEN}

Introducción. La depresión y la disfunción ejecutiva comparten varias características neurocognitivas, y ambas a menudo afectan áreas de funcionamiento de la vida cotidiana, como el trabajo. El efecto de su interacción en este desenlace es, sin embargo, apenas conocido. Objetivo. Fue analizar el efecto moderador del funcionamiento ejecutivo (FE) en la relación entre la gravedad de depresión y el desempeño laboral (presentismo y ausentismo). Método. Los datos se recopilaron no probabilísticamente por medio de una encuesta en línea. Se emplearon análisis de regresión lineal jerárquica para probar la hipótesis principal, con sintomatología depresiva (PHQ-9) y FE (BRIEF-A) como predictores, y presentismo (SPS-6) y ausentismo (HPQ) como variables de desenlace independientes. Resultados. Se analizaron 462 participantes. Los modelos de regresión no mostraron interacciones significativas, sólo efectos aditivos de la gravedad de depresión y la FE sobre el presentismo, y no hubo ningún efecto de estas variables sobre el ausentismo. Discusión y conclusión. Nuestro hallazgo principal discrepa de otros que reportan efectos moderadores de FE para otras variables psicológicas. Hipotetizamos que las alteraciones de FE pueden tener características particulares para la depresión (por ejemplo, inflexibilidad cognitiva en la rumiación del pensamiento), que no son evaluadas por el BRIEF-A. Es recomendable que estudios futuros empleen tareas de desempeño para medición de efecto moderador de FE, y considerar indicadores naturalistas de desempeño laboral.

Palabras clave: Depresión, funciones ejecutivas, desempeño laboral, presentismo, ausentismo. 


\section{INTRODUCTION}

Though traditionally addressed as a disorder with emotional symptomatology at its core, depression can also be understood as an alteration of cognition, particularly executive functions (EFs) (Hammar \& Årdal, 2009; Millan et al., 2012; Snyder, 2013). This is so because: a) the very signs and symptoms of depression are akin to those of the dysexecutive syndrome (Godefroy et al., 2010), e.g., abulia (a deficit of behavior initiation), inability to concentrate (often due to lack of inhibition of depressive thoughts), or cognitive inflexibility (observed in thought rumination) (Watkins \& Brown, 2002); b) anomalies in frontal lobe networks commonly found in cases of executive dysfunction have also been observed in cases of depression (Bracht, Linden, \& Keedwell, 2015; Goodwin, 2016); c) poor performance on a wide variety of EFs' tasks have been steadily observed too (Hammar \& Årdal, 2009; Snyder, 2013).

One of the common critical features of both depression and dysexecutive functioning is that they often lead to significant impairment on areas of everyday life functioning (American Psychiatric Association, 2013; Millan et al., 2012; Villalobos-Gallegos et al., 2019), such as work. In fact, as close as $50 \%$ of lost productive time may be explained by depression (Stewart, Ricci, Chee, Hahn, \& Morganstein, 2003), and work-related stressors are significant risk factors of this disorder (Bonde, 2008). For its part, ADHD, a common EF-related disorder, has been associated with lost of productivity across diverse samples of workers (Kessler et al., 2005), and ADHD-related EFs' deficits have been found to be associated with a higher frequency of unemployment (Halleland, Sørensen, Posserud, Haavik, \& Lundervold, 2015).

As relevant as this evidence is, to our knowledge, there has not been an analysis of the moderating effect of executive function between depression and work performance. Given the close relation these constructs have, it seems plausible that such interaction may help to better explain the variation on indicators of work performance. A moderating effect of EFs has been observed, for example, between: behavioral intention and behavioral performance (Hall, Fong, Epp, \& Elias, 2008; Hall, Zehr, Paulitzki, \& Rhodes, 2014), perceived stress and aggressive behavior (Sprague, Verona, Kalkhoff, \& Kilmer, 2011), and in interventions for promoting socio-emotional functioning (Riggs, Jahromi, Razza, Dillworth-Bart, \& Mueller, 2006).

The objective of this study was to analyze the interactive effect of EF and depression severity on variables of work performance (presenteeism and absenteeism). We hypothesize that the expected correlations between depression and work performance variables are boosted by the moderating effects of higher levels of dysexecutive functioning. Overall, our purpose is to add evidence to the understanding of depression as impairment of EFs, and its impact on a specific clinical outcome.

\section{METHOD}

\section{Study design}

Cross-sectional web-based survey.

\section{Participants}

A non-clinical sample of economically active individuals was recruited across the Mexican territory via a web-based survey, using a non-probabilistic snowball sampling technique by which potential or enrolled participants invited their own acquaintances to participate in the study. Recruitment lasted one month, from September $15^{\text {th }}$ through October $18^{\text {th }}, 2018$. Eligibility criteria were: $18-60$ years of age (in order to maximize probability of having a job and to minimize the risk for age-associated cognitive decline), currently having a job with at least three months of non-interrupted activity, and having understood and accepted the informed consent.

\section{Measures}

\section{Demographic questionnaire}

It included items about gender, years of age, and education attainment.

\section{Patient Health Questionnaire (PHQ-9)}

A Spanish-adapted version was used to measure the severity of depression. The PHQ-9 consists on nine items which inquires the respondent about specific depressive symptoms (corresponding to DSM-IV criteria) in the last two weeks, according to a Likert scale with 0 -to-3 values. A total score is computed, with upper values indicating a higher severity of depression. Ordinal levels of depression severity can also be concluded from this score as follows: 0-4 = none, 5-9 = mild, 10-14 = moderate, $15-19=$ moderately severe, 20-27 $=$ severe (Kroenke, Spitzer, \& Williams, 2001). The PHQ-9 is a very common scale in clinical research worldwide; evidence of its validity has been reported for Latin American populations (Cassiani-Miranda, Vargas-Hernández, Pérez-Aníbal, Herazo-Bustos, \& Hernández-Carrillo, 2017), and it has been used for research with different Mexican samples (Romo Nava, Tafoya, \& Heinze, 2013).

\section{Health and Work Performance Questionnaire (HPQ)}

Two items from this questionnaire were used for measuring absenteeism: 1 . number of work hours expected by the employer in the past seven days, and 2. number of hours worked in the past seven days (Kessler et al., 2004). The value to consider in the main analysis was the quotient of item 2 divided by item 1 and multiplied by 100 to obtain a percentage. For those cases in which there was no employer or there were no expected work hours, the value of that item 
was set equal to item 2. The HPQ is recommended by the World Health Organization and it has been widely used in complete and partial versions across different studies (Wang et al., 2003). It has provided evidence of validity by obtaining significant correlations ( $r$ values ranging from .61 to .81) with employer payroll records in multiple occupations (Kessler et al., 2004).

\section{Stanford Presenteeism Scale (SPS-6)}

It evaluates the possible decreased productivity or below-normal work quality of an employee when he/she is physically present in his/her job (Kessler et al., 2004). Aiming to reduce friction to respond the survey, we used a short version consisting of six items inquiring the respondent about his/her work experiences in the past month in relation to a health problem. For this study, and as recommended by the authors of the scale, we defined "health problem" as "emotional state" within the statements of the items. Response options were displayed in a five-level Likert scale (Strongly disagree $=1$, Somewhat disagree $=2$, Uncertain $=$ 3 , Somewhat agree $=4$, Strongly agree $=5$ ), and are summed up (after reversing items 1, 3, and 4) to obtain a total score, with higher values indicating a better ability to concentrate and to have accomplishments at work in spite of health problems. Good concurrent validity was reported for this instrument compared to the original 32-item version, and good internal consistency (Cronbach's alpha $=.80)($ Koopman et al., 2002). Since there is no Spanish language version of the SPS-6, we translated the items and tested their readability within a pilot study with 30 participants, all of them reporting good understanding of the items.

\section{Behavior Rating Inventory of Executive \\ Functions - Brief Version for Adults (BRIEF-A)}

This inventory assesses executive functions in everyday life (Roth, Lance, Isquith, Fischer, \& Giancola, 2013). Again, with the intention of reducing friction to respond the survey, we used a Spanish-translated abbreviated 17-item version (Basuela Herreras, 2016). The BRIEF-A displays statements concerning difficulties related to the control of goal-oriented behavior and asks the respondent to grade his/ her own behavior according with the options: Never $=1$, Sometimes $=2$, and Often $=3$. A total score can be computed, with higher scores indicating more severity of executive dysfunction.

\section{Procedure}

The online survey was designed and implemented using Google Forms. Following guidelines for online research (Regmi, Waithaka, Paudyal, Simkhada, \& van Teijlingen, 2016), the link to the survey was originally sent to authors' acquaintances via social networks (WhatsApp and Facebook), with a brief message encouraging both participation and forwarding of the link and message to other respective acquaintances, independently of participating or not in the study. Once the potential participant opened the link, the informed consent was displayed explaining objectives, activities, voluntary participation, confidentiality, low risk, and possibility of return of individual results (participants who completed evaluation were given the option to provide an individual e-mail, stressing that this will be the only identification data to collect, and a general description of the results, including levels of depression, executive dysfunction, and presenteeism, was sent to them after collection of data). Before beginning with the survey, potential participants were inquired about understanding of informed consent and acceptance of participation; when responding negatively to one of these questions, the survey ended; when not, participants underwent the full evaluation with this sequence: PHQ-9, HPQ, SPS-6, and BRIEF-A.

Ethical considerations adhered to the Declaration of Helsinki.

\section{Statistical analysis}

Flow of participants was described from recruitment to final sample to be analyzed. Variables of interest were described using mean (standard deviation) and frequencies (percentages) for numerical and categorical data, respectively. Aiming to identify empirically-based confounders, differences between main variables were tested in relation to gender (Student's $t$ ) and degree of education (ANOVA), and Pearson product-moment correlation analyses were performed to test for associations with age.

To test for the main hypothesis of the study, two hierarchical linear regression analyses were performed. The first analysis compared three hierarchical steps defined by the following predictors of presenteeism: 1. depression severity; 2. depression severity and EF; and 3. depression severity, EF, and depression severity $\times$ EF. Previously identified confounders where controlled in a fourth step. The second analysis was structured in a similar fashion with absenteeism as the outcome variable. Models were compared using $\Delta R^{2}$ to test for significant change in outcomes' explained variance.

A $p$-value $<.05$ was set to determine statistical significance. Cases were automatically excluded from specific analyses when missing data in the computed variables (e.g., PHQ-9 total score). IBM SPSS Statistics version 25 was used for all the analyses.

\section{RESULTS}

Five hundred and fourteen individuals were initially recruited, excluding: one (.2\%) because of incomprehension of informed consent, one $(.2 \%)$ for rejecting participation, six $(1.2 \%)$ because of not meeting age criterion, 30 (5.8\%) for 
Table 1

Characteristics of the participants

\begin{tabular}{|c|c|c|}
\hline & Mean (SD) & or Freq. (\%) \\
\hline \multicolumn{3}{|l|}{ Demographics } \\
\hline Age $(n=462)$ & 33.7 & (11.4) \\
\hline \multicolumn{3}{|l|}{ Gender $(n=462)$} \\
\hline Women & 301 & $(65.2)$ \\
\hline Men & 161 & $(34.8)$ \\
\hline \multicolumn{3}{|l|}{ Education degree $^{a}$} \\
\hline Elementary-High school & 24 & $(5.2)$ \\
\hline College & 321 & $(69.6)$ \\
\hline Post-graduate & 116 & $(25.2)$ \\
\hline PHQ-9: Total score $(n=460)^{\mathrm{b}}$ & 5.9 & $(4.9)$ \\
\hline \multicolumn{3}{|l|}{ Work performance } \\
\hline HPQ: Expected hours/Worked hours ${ }^{c}$ & 119.3 & $(108.8)$ \\
\hline SPS-6: Total score ${ }^{d}$ & 21.5 & $(4.6)$ \\
\hline BRIEF-A: Total score & 11.2 & $(5.8)$ \\
\hline
\end{tabular}

Notes: a One missing value; ${ }^{\mathrm{b}}$ Two missing values; ‘ 21 missing values; ${ }^{\mathrm{d}}$ Three missing values; e 13 missing values.

Abbreviations: BRIEF-A, Behavior Rating Inventory of Executive FunctionAdult brief version; HPQ, Health and Work Performance Questionnaire; PHQ9, Patient Health Questionnaire; SPS-6, Stanford Presenteeism Scale.

not meeting the criterion of at least three months working, seven $(1.3 \%)$ repeated cases (based on repetition of personal e-mail provided for devolution of results), and two (.4\%) cases with extreme values in the indicators of absenteeism. A total of 462 cases were included in the analyses.

Characteristics of participants are shown in Table 1. The sample was mostly constituted by women $(65.1 \%)$, with an overall range of age between 18-60 years-old, and virtually all the sample distributed within the highest degrees of education (92\%). Concerning diagnostic results of the PHQ-9: $47.6 \%$ qualified as not being depressed, $34.6 \%$ for mild depression, and $17.8 \%$ for moderate to severe depression.

No significant difference was observed regarding main variables and gender, but one was observed for depression within education degree $(F[2,471]=5.37, p<.05)$, particularly in relation to elementary-to-high school level vs college and postgraduate levels; however, since most of the sample was in the higher education degrees, this variable was not finally treated as a confounder. Age did significantly correlate with all the main variables ( $r$ ranging from -.12 to .20$)$, so it was included as a covariate within the main analyses.

Concerning the hierarchical linear regression models (Table 2), significant prediction of presenteeism was found for depression (model 1.1), and for depression + EF (model 1.2 ), with a significant change in $R^{2}$ value (predicting $25 \%$ of the variation of presenteeism vs. $23 \%$ of model 1.1 ), but no significant change was found when adding the interactive term depression severity $\times \mathrm{EF}$ (model 1.3). Controlling for age confounder, a significant change in $R^{2}$ was found (predicting 26\% of the variation of presenteeism). Regarding prediction of absenteeism, only depression resulted in a single significant association (model 2.1), and thus no change in R2 was observed for the subsequent models.

\section{DISCUSSION}

The objective of this study was to analyze the moderating effect of EF between depression severity and work performance. Based on the results, no significant interaction was found, but only additive effects of depression severity and $\mathrm{EF}$ on presenteeism, and no effect of these variables on absenteeism. This indicates that sadness, apathy, abulia, anhedonia, and other symptoms of depression (Kroenke et al., 2001) deplete the capacity of the worker to concentrate and achieve goals at his/her workplace, and so do, independently, symptoms of impulsivity, cognitive inflexibility and disorganization, difficulties for behavior initiation, self-monitoring, and working memory deficits (Roth et al., 2013). However, interaction in the form of sadness potentiated by cognitive inflexibility, or abulia potentiated by lack of behavior initiation, was not found.

Our main finding disagrees with those reported about the moderating effects of specific EFs between other psychological variables (Hall et al., 2008; 2014; Sprague et al., 2011), and is somewhat conflicted with the understanding of depression as a form of EF alteration (Millan et al., 2012; Snyder, 2013). The use of the BRIEF-A, which evaluates EF impairment close to the diagnostic criteria for ADHD, may have contributed to this lack of interaction. In this sense, we hypothesize that $\mathrm{EF}$ alterations may have particular features for specific psychiatric disorders, in a similar fashion to the distinction of hot and cold EFs (Moreno-López et al., 2012) for specific neuropsychological tasks and daily-life activities. For example, hot EFs, which encompass emotional regulation and decision-making, may have a more crucial involvement in depression than cold EFs, which relates to the use of mental regulation for the execution of cognitive tasks. Development of self-report scales with items aiming to explore dysexecutive functions in close relation to depression symptomatology may be useful in this regard (e.g., for cognitive inflexibility: "I have difficulties thinking in something else besides sad thoughts").

The univariate effects of depression severity and EF on presenteeism are in accordance with previous findings (Kessler et al., 2005; Stewart et al., 2003). The lack of meaningful associations with absenteeism may be explained by the fact that most of the sample qualified for mild depression, which may suppose enough functionality for attending to the workplace; additionally, in individuals with mild-to-moderate depression, the perspective of job dismissal may function as a more potent stimulus for the conditioning of behavior than the inner stimuli of the depression. These suppositions may be further strengthened by the fact that presenteeism did associate with our predictors, meaning that, despite at- 
Table 2

Hierarchical linear regression analyses testing the moderating effect of executive functioning between depression and variables of work performance

\begin{tabular}{|c|c|c|c|c|c|c|c|}
\hline \multirow[b]{2}{*}{ Models } & \multirow[b]{2}{*}{ Measures } & \multicolumn{2}{|c|}{ Unstandardized coefficient } & \multirow[b]{2}{*}{$p$} & \multirow[b]{2}{*}{$F$} & \multirow[b]{2}{*}{$R^{2}$} & \multirow[b]{2}{*}{$\Delta R^{2}$} \\
\hline & & $B$ & SE & & & & \\
\hline \multicolumn{8}{|c|}{ Outcome: SPS-6 total score $(n=445)$} \\
\hline \multirow[t]{3}{*}{1.1} & - & - & - & - & $135.10(1,443)$ & .23 & - \\
\hline & Constant & 24.19 & .30 & .00 & - & - & - \\
\hline & PHQ-9 & -0.45 & .03 & .00 & - & - & - \\
\hline \multirow[t]{4}{*}{1.2} & - & - & - & - & $11.34(1,442)$ & .25 & .00 \\
\hline & Constant & 25.15 & .41 & .00 & - & - & - \\
\hline & PHQ-9 & -.36 & .04 & .00 & - & - & - \\
\hline & BRIEF-A & -.13 & .03 & .00 & - & - & - \\
\hline \multirow[t]{5}{*}{1.3} & - & - & - & - & $.23(1,441)$ & .25 & .62 \\
\hline & Constant & 25.37 & .61 & .00 & - & - & - \\
\hline & PHQ-9 & -.40 & .09 & .00 & - & - & - \\
\hline & BRIEF-A & -.15 & .05 & .00 & - & - & - \\
\hline & PHQ-9×BRIEF-A & .00 & .00 & .62 & - & - & - \\
\hline \multirow[t]{6}{*}{1.4} & - & - & - & - & $.23(1,441)$ & .26 & .006 \\
\hline & Constant & 23.62 & .87 & .00 & - & - & - \\
\hline & PHQ-9 & -.38 & .09 & .00 & - & - & - \\
\hline & BRIEF-A & -.14 & .05 & .01 & - & - & - \\
\hline & PHQ-9×BRIEF-A & .002 & .006 & .71 & - & - & - \\
\hline & Age & .04 & .01 & .006 & & & \\
\hline \multicolumn{8}{|c|}{ Outcome: HPQ Expected hours/Worked hours $(n=427)$} \\
\hline \multirow[t]{3}{*}{2.1} & - & - & - & - & $4.16(1,425)$ & .01 & - \\
\hline & Constant & 106.89 & 8.41 & .00 & - & - & - \\
\hline & PHQ-9 & 2.25 & 1.10 & .04 & - & - & - \\
\hline \multirow[t]{4}{*}{2.2} & - & - & - & - & $.21(1,424)$ & .01 & .64 \\
\hline & Constant & 103.16 & 11.62 & .00 & - & - & - \\
\hline & PHQ-9 & 1.91 & 1.33 & .15 & - & - & - \\
\hline & BRIEF-A & .51 & 1.10 & .64 & - & - & - \\
\hline \multirow[t]{5}{*}{2.3} & - & - & - & - & $.14(1,423)$ & .01 & .70 \\
\hline & Constant & 107.99 & 17.27 & .00 & - & - & - \\
\hline & PHQ-9 & 1.03 & 2.66 & .69 & - & - & - \\
\hline & BRIEF-A & .08 & 1.57 & .95 & - & - & - \\
\hline & PHQ-9×BRIEF-A & .06 & .16 & .70 & - & - & - \\
\hline \multirow[t]{6}{*}{2.4} & - & - & - & - & $1.18(1,422)$ & .01 & .70 \\
\hline & Constant & 87.72 & 25.35 & .00 & - & - & - \\
\hline & PHQ-9 & 1.44 & 2.68 & .59 & - & - & - \\
\hline & BRIEF-A & .18 & 1.57 & .90 & - & - & - \\
\hline & PHQ-9×BRIEF-A & .05 & .16 & .75 & - & - & - \\
\hline & Age & .52 & .48 & .27 & - & - & - \\
\hline
\end{tabular}

Abbreviations: BRIEF-A, Behavior Rating Inventory of Executive Function- Adult brief version; HPQ, Health and Work Performance Questionnaire; PHQ-9, Patient Health Questionnaire; SPS-6, Stanford Presenteeism Scale.

tending work, performance is still compromised by depressive and dysexecutive symptoms.

There are limitations to consider. First, the generalisability is minimized by the sampling method, which restricted the education of the participants to the highest degrees, and most likely restricted the socioeconomical status to middle- and high-income individuals too. Moderating effects of cognitive reserve may have played a role because of this demographic bias, particularly in the expression of EFs; we tried to temper this limitation with the snowball recruitment and social networks, however, further studies evaluating a more diverse demographic samples are needed in order to corroborate the findings. Second, web-based surveys come with inherent limitations, like a higher probability of misunderstanding of items or multiple responses from the same participant (Regmi et al., 2016). We tried to 
minimize this by using brief and easy-to-understand scales, by providing the instruction not to response twice, and by eliminating possible duplicated cases from the final database. Third, though we used widely-employed psychometrically valid measures, self-reports leave aside important behavioral information provided by EF tasks and naturalistic indicators of work performance; future studies should test our findings by solving this limitation.

\section{Funding}

None.

\section{Conflict of interest}

None.

\section{Author's contributions}

SA-T, MQ-B, VQ-B, and MG-B conceptualized and designed the study, collected and performed analysis of the data. AT-F guided the study design, supervised the data collection, and performed the main statistical analysis. All authors participated in the interpretation of the results, drafted and approved the final version of the manuscript.

\section{REFERENCES}

American Psychiatric Association. (2013). Diagnostic and Statistical Manual of Mental Disorders (DSM-5®) (Fifth edition). Arlington, VA: American Psychiatric Association. doi: 10.1176/appi.books.9780890425596.744053

Basuela Herreras, E. (2016). BRIEF-A (forma abreviada): Análisis propiedades psicométricas en una muestra española. Archivos de Neurociencias, 21(4), 6-15. https://www.medigraphic.com/pdfs/arcneu/ane-2016/ane164a.pdf

Bonde, J. P. E. (2008). Psychosocial factors at work and risk of depression: a systematic review of the epidemiological evidence. Occupational and Environmental Medicine, 65(7), 438-445. doi: 10.1136/oem.2007.038430

Bracht, T., Linden, D., \& Keedwell, P. (2015). A review of white matter microstructure alterations of pathways of the reward circuit in depression. Journal of Affective Disorders, 187, 45-53. doi: 10.1016/j.jad.2015.06.041

Cassiani-Miranda, C. A., Vargas-Hernández, M. C., Pérez-Aníbal, E., HerazoBustos, M. I., \& Hernández-Carrillo, M. (2017). Confiabilidad y dimensión del cuestionario de salud del paciente ( PHQ-9 ) para la detección de síntomas de depresión en estudiantes de ciencias de la salud en Cartagena, 2014. Biomédica, 37(Suppl 1), 112-120. doi: 10.7705/biomedica.v37i0.3221

Godefroy, O., Azouvi, P., Robert, P., Roussel, M., LeGall, D., \& Meulemans, T. (2010). Dysexecutive syndrome: Diagnostic criteria and validation study. Annals of Neurology, 68(6), 855-864. doi: 10.1002/ana.22117

Goodwin, G. M. (2016). Neuropsychological and neuroimaging evidence for the involvement of the frontal lobes in depression : 20 years on. Journal of Psychopharmacology, 30(11), 1090-1094. doi: 10.1177/0269881116661074

Hall, P. A., Fong, G. T., Epp, L. J., \& Elias, L. J. (2008). Executive function moderates the intention-behavior link for physical activity and dietary behavior. Psychology \& Health, 23(3), 309-326. doi: 10.1080/14768320701212099

Hall, P. A., Zehr, C., Paulitzki, J., \& Rhodes, R. (2014). Implementation intentions for physical activity behavior in older adult women : An examination of executive function as a moderator of treatment effects. Annals of Behavioral Medicine, 48(1), 130-136. doi: 10.1007/s12160-013-9582-7

Halleland, H. B., Sørensen, L., Posserud, M. B., Haavik, J., \& Lundervold, A. J. (2015). Occupational status is compromised in adults with ADHD and psychometrically defined executive function deficits. Journal of Attention Disorders, 23(1), 76-86. doi: 10.1177/1087054714564622

Hammar, Å. \& Årdal, G. (2009). Cognitive functioning in major depression - a summary. Frontiers in Human Neuroscience, 3(September), 26. doi: 10.3389/ neuro.09.026.2009
Kessler, R. C., Adler, L., Ames, M., Barkley, R. A., Birnbaum, H., Greenberg, P., ... \& Üstün, T. B. (2005). The Prevalence and Effects of Adult Attention Deficit/ Hyperactivity Disorder on Work Performance in a Nationally Representative Sample of Workers. Journal of Occupational and Environmental Medicine, 47(6), 565-572. doi: 10.1097/01.jom.0000166863.33541.39

Kessler, R. C., Ames, M., Hymel, P. A., Loeppke, R., Mckenas, D. K., Richling, D. E., \& Stang, P. E. (2004). Using the World Health Organization Health and Work Performance Questionnaire (HPQ) to evaluate the indirect workplace costs of illness. Journal of Occupational and Environmental Medicine, 46(6), S23-S37. doi: 10.1097/01.jom.0000126683.75201.c5

Koopman, C., Pelletier, K. R., Murray J. F., Sharda, C. E., Berger, M. L., Turpin, R. S., ... \& Bendel, T. (2002). Stanford Presenteeism Scale : Health status and employee productivity. Journal of Occupational and Environmental Medicine, 44(1), 14-20. doi: 10.1097/00043764-200201000-00004

Kroenke, K., Spitzer, R. L., \& Williams, J. B. W. (2001). The PHQ-9: Validity of a brief depression severity measure. Journal of General Internal Medicine, 16(9), 606-613. doi: 10.1046/j.1525-1497.2001.016009606.x

Millan, M. J., Agid, Y., Brüne, M., Bullmore, E. T., Carter, C. S., Clayton, N. S., ... \& Young, L. J. (2012). Cognitive dysfunction in psychiatric disorders: characteristics, causes and the quest for improved therapy. Nature Reviews Drug Discovery, $11(2), 141-168$. doi: $10.1038 / \operatorname{nrd} 3628$

Moreno-López, L., Stamatakis, E. A., Fernández-Serrano, M. J., Gómez-Río, M., Rodríguez-Fernández, A., Pérez-García, M., \& Verdejo-García, A. (2012). Neural correlates of hot and cold executive functions in polysubstance addiction: Association between neuropsychological performance and resting brain metabolism as measured by positron emission tomography. Psychiatry Research - Neuroimaging, 203(2-3), 214-221. doi: 10.1016/j.pscychresns.2012.01.006

Regmi, P. R., Waithaka, E., Paudyal, A., Simkhada, P., \& van Teijlingen, E. (2016). Guide to the design and application of online questionnaire surveys. Nepal Journal of Epidemiology, 6(4), 640-644. doi: 10.3126/nje.v6i4.17258

Riggs, N. R., Jahromi, L. B., Razza, R. P., Dillworth-Bart, J. E., \& Mueller, U. (2006). Executive function and the promotion of social-emotional competence. Journal of Applied Developmental Psychology, 27(4), 300-309. doi: 10.1016/j. appdev.2006.04.002

Romo Nava, F., Tafoya, S. A., \& Heinze, G. (2013). Estudio comparativo sobre depresión y los factores asociados en alumnos del primer año de la Facultad de Medicina y del Internado. Salud Mental, 36(5), 375-379.

Roth, R. M., Lance, C. E., Isquith, P. K., Fischer, A. S., \& Giancola, P. R. (2013). Confirmatory Factor Analysis of the Behavior Rating Inventory of Executive Function-Adult Version in healthy adults and application to attention-deficit/ hyperactivity disorder. Archives of Clinical Neuropsychology, 28(5), 425-434. doi: 10.1093/arclin/act031

Snyder, H. R. (2013). Major depressive disorder is associated with broad impairments on neuropsychological measures of executive funtion: A meta-analysis and review. Psychological Bulletin, 139(1), 81-132. doi: 10.1037/a0028727

Sprague, J., Verona, E, Kalkhoff, W., \& Kilmer, A. (2011). Moderators and mediators of the stress-aggression relationship: Executive function and state anger. Emotion, 11(1), 61-73. doi: 10.1037/a0021788

Stewart, W. F., Ricci, J. A., Chee, E., Hahn, S. R., \& Morganstein, D. (2003). Cost of lost productive work time among US workers with depression. JAMA: The Journal of the American Medical Association, 289(23), 3132-3144. doi: 10.1001/jama.289.23.3135

Villalobos-Gallegos, L., Medina-Mora, M. E., Benjet, C., Ruiz-Velasco, S., MagisRodriguez, C., \& Marín-Navarrete, R. (2019). Multidimensional patterns of sexual risk behavior and psychiatric disorders in men with substance use disorders. Archives of Sexual Behavior, 48(2), 599-607. doi: 10.1007/s10508-018-1227-2

Wang, P. S., Beck, A., Berglund, P., Leutzinger, J. A., Pronk, N., Richling, D., ... \& Kessler, R. C. (2003). Chronic medical conditions and work performance in the health and work performance questionnaire calibration surveys. Journal of Occupational and Environmental Medicine, 45(12), 1303-1311. doi: 10.1097/01.jom.0000100200.90573.df

Watkins, E. \& Brown, R. G. (2002). Rumination and executive function in depression: an experimental study. Journal of Neurology, Neurosurgery and Psychiatry, 72(3), 400-402. doi: 10.1136/jnnp.72.3.400 